\title{
Seminal Fluid Characteristics of Men Attending Infertility Clinic of a Teaching Hospital
}

\author{
Festus Abiose Olajubu ${ }^{*}$, Deji-Agboola Mope ${ }^{2}$, Olubunmi Adetokunbo Osinupebi ${ }^{2}$, \\ Olusoji Edward Jagun ${ }^{3}$ \\ ${ }^{1}$ Department of Medical Microbiology \& Parasitology, Olabisi Onabanjo University Teaching Hospital, \\ Sagamu, Nigeria \\ ${ }^{2}$ Department of Medical Microbiology \& Parasitology, Obafemi Awolowo College of Health Sciences, \\ Olabisi Onabanjo University, Sagamu, Nigeria \\ ${ }^{3}$ Department of Obstetrics and Gynaecology, College of Health Sciences, Olabisi Onabanjo University, Sagamu, Nigeria \\ Email: *Olajubufa@yahoo.com
}

Received November 15, 2012; revised December 20, 2012; accepted December 31, 2012

\begin{abstract}
The semen quality of 479 men in infertile marriages, who attended the infertility clinic of OOUTH, Sagamu between May 2004 and April 2009 were analyzed. The semen samples were physically examined, microscopically analyzed and aerobically cultured. The result showed that out of 51.5\% oligospermic cases recorded, $39.8 \%$ could be classified severe. Cryptozoospermia were diagnosed in 72 (15\%) cases. Bacteriospermia and Necrozoospermia were found in 149 and 6 cases respectively. The predominant organism isolated was Staphylococcus aureus (50.32\%) while Neisseria gonorrhoea was isolated in only 2 cases. Highest infection of $62.4 \%$ was noticed among the group with $1 \%-19 \%$ motility. From the studied population, $8.8 \%$ were azoospermic. The commonest morphological defects were pin and ragged heads (48\%). It is therefore obvious that the assessment of semen quality remains one of the important steps in infertility interventions.
\end{abstract}

Keywords: Sperm Concentration; OOUTH; Infertile Marriages; Motility; Bacteriospermia

\section{Introduction}

The coming together of a man and a woman in marriage in the Nigerian socio-cultural context is primarily for procreation. Anxiety sets in when this is not achieved within a stipulated period of time. It is often followed by emotional stress and domestic strife. It also creates social strains with friends, family members and colleagues [1, 2].

Research has provided much insight into the feelings of individual and the social consequences of infertility [3].

Infertility in the general context is described as a situation where a couple does not succeed in achieving pregnancy in spite of unprotected sexual intercourse over a period of 12 months [2,4]. In male, infertility is defined as the inability of the male reproductive cells to produce mature, actively motile and functional spermatozoa in sufficient amount that will ensure fertilization of a released ovum in the fallopian tubes [5]. Usually, the woman bears the blame of infertile marriages, especially when the man is able to achieve normal erection and

${ }^{*}$ Corresponding author. ejaculation. Virility is thus thought to be synonymous with fertility [6,7]. Since the quality of seminal fluid cannot be physically assessed, intervention of the medical laboratory is often sought.

Infertility is a global problem affecting approximately $10 \%-15 \%$ of married couples. Global variation has been reported in the incidence of infertility from as low as $1 \%$ to $1.5 \%$ in Korea and Thailand to as high as $13 \%-23 \%$ in urban areas of Columbia and rural areas of New Guinea. The prevalence of infertility is particularly high in sub-Saharan African, varying from $20 \%-40 \%$ in some parts of West Africa. The World Health Organization reveals that male reproductive capacity is deficient in not less than $50 \%$ of infertile couples in several countries of the world. In Africa, up to $65 \%$ of gynaecological consultations are for infertility $[2,8,9]$.

There are many factors that are associated with infertility in man. These include; the presence of varicocele, sexual dysfunction, genitourinary infections, urospermia, age and nutrition. Other factors include stress and emotions, endocrine and chromosomal abnormalities, excessive alcohol consumption, environmental factors and non-diagnosable causes. Labour migration also separates 
husband and wife, hence reducing exposure of the wife to sexual intercourse [10-13].

In diagnosing infertility in male, Computer-Assisted Sperm Analysis (CASA), which allows an objective assessment of different cell characteristics, is in use in some parts of the world [14].

However, in many parts of Nigeria, semen analysis is routinely done through the conventional microscopy method. Culture, hormonal evaluation and special sperm function tests (sperm-cervical mucus interaction, sperm penetration assay etc.) are beneficial. For a clinician, evaluation of seminal quality is linked with a desire to predict potential fertility, identify causes of infertility or detect changes in potential fertility $[2,14]$.

Onemu and Ibeh found that the presence of bacteria in semen (bacteriospermia) might be an early warning signal (EWS) to taking important steps in the prevention and management of male infertility [15].

This study was designed to assess the quality of seminal fluid of men in infertile marriages who attended the gynaecology clinic of Olabisi Onabanjo University Teaching Hospital, Sagamu-Nigeria between May 2004 and April 2009, with a view to identify the possible contribution of the male factor to overall infertility problems in this environment.

Olabisi Onabanjo University Teaching Hospital (OO UTH) is strategically located at Sagamu, where it serves patients from all parts of the State and neighbouring states of Lagos, Ondo and Oyo. Infertility cases constitute $14.8 \%$ of all gynaecological consultations in this hospital [16].

\section{Materials and Methods}

The results of seminal fluid analysis of men being investigated in infertile marriages at Olabisi Onabanjo University Teaching Hospital, Sagamu, Ogun State, SouthWest of Nigeria were collated. The study involved all males who attended the infertility clinic of the hospital with their mates between May 2004 and April 2009, a period of five years. A total of 479 men were, investigated.

Pre-production counseling was given to all the par- ticipants. These include abstinence from sexual intercourse or masturbation for a period of 3 - 5 days and avoiding the use of antibiotics prior to collection especially in cases where culture is required. Agreement was equally reached with each participant on the mode of production and time lapse between production and analysis of specimen [14].

About $85 \%$ of the samples were collected through masturbation, while others by coitus interruptus. The samples were asceptically collected into sterile universal bottles provided by the hospital. The semen samples were then examined for physical parameters e.g. colour, volume, viscosity, coagulation and liquefaction. The percentage motility and sperm concentration were calculated according to WHO approved standard [14]. All samples were examined within an hour after production. The samples were stained for morphological assessment using Giemsa stain.

The samples were further examined bacteriologically. They were cultured on freshly prepared heated blood agar (in duplicate) and MacConkey agar plates. A set of the inoculated heated blood agar plates was incubated in an increased carbon dioxide (10\%) environment. Others were incubated aerobically at $37^{\circ} \mathrm{C}$ for between 24 to 48 hours.

The bacteria growths were identified using standard methods [17]. The antibiogram of the isolates were determined by agar diffusion method.

\section{Results}

A total of 479 men were examined for the quality of their seminal fluid. The mean of the first two analysis carried out within 4 - 6 weeks were used for the purpose of this study. A total of 94 (19.6\%) and 385 (80.4\%) cases presented with primary and secondary infertility respectively. The analysis of sperm concentration is shown in Table 1 where $39.7 \%$ of the total attendee had sperm count of 20 million cells per milliliter of seminal fluid and above. Forty-two men were azoospermic. Assessment result of the percent motility, an important factor in assessing seminal fluid quality is shown in Table 2. From this table, it is noticed that six men were necrozoospermic. However 181 (41.42\%) had motility of 50\% and above. The morphological defects vary between $65 \%$ $75 \%$ in 392 of sample examined. The most common defects were ragged heads and broken tails. Ninety-three out of the 149 bacteriospermic cases recorded in this study falls within $1 \%-19 \%$ motility range as shown in Table 3. It is equally important to note that 4 (66.7\%) of azoospermic cases were equally infected. From Table 4, Staphylococcus aureus was isolated in 78 (50.32\%) semen samples, Candida albicans in 8 and Neisseria gonorrhoea in 2.

\section{Discussion}

This study showed that $8.8 \%$ of the study populations were azoospermic. This is the only group one can categorically say may be fully responsible for the couple's infertility, since they are sterile.

About 51.5\% whose sperm concentrations were below $20 \times 10^{6}$ cells/ml could equally be a source or contributory to infertility. This might as well confirm the statement that about half of infertility cases have their origin in the male counterpart $[2,8]$. 
Table 1. The sperm concentration of attendees in millions $/ \mathrm{ml}$.

\begin{tabular}{cccccccc}
\hline Sperm count in Million cells/ml & $\mathbf{2 0}$ & $\mathbf{1 0}-\mathbf{1 9}$ & $\mathbf{1 ~ - 9}$ & $<$ & $\mathbf{0}$ & Total \\
\hline No. of Men & 190 & 56 & 119 & 72 & 42 & 479 \\
\% of Total & 39.7 & 11.7 & 24.8 & 15.0 & 8.8 & 100 \\
\hline
\end{tabular}

Table 2. The motility assessment of semen of attendees expressed in \%.

\begin{tabular}{cccccc}
\hline \% Motility & $\mathbf{2 5 0}$ & $\mathbf{2 0 - 4 9}$ & $\mathbf{1 - 1 9}$ & $\mathbf{0}$ & Total \\
\hline No. of Men & 181 & 98 & 152 & 06 & 437 \\
\% of Total & 41.4 & 22.4 & 34.8 & 1.4 & 100 \\
\hline
\end{tabular}

Table 3. Seminal fluid infection in relation to motility.

\begin{tabular}{cccccc}
\hline \% Motility & $\mathbf{2 5 0}$ & $\mathbf{2 0}-\mathbf{4 9}$ & $\mathbf{1 - 1 9}$ & $\mathbf{0}$ & Total \\
\hline No. of Sample with Pathogen & 17 & 35 & 93 & 4 & 149 \\
\% of Total & 11.4 & 23.5 & 62.4 & 2.7 & 100 \\
\hline
\end{tabular}

Table 4. Microorganism isolated from the attendees' semen samples.

\begin{tabular}{ccc}
\hline Organisms & Frequency of Isolate & $\mathbf{\%}$ \\
\hline Klebsiella sp. & 13 & 8.39 \\
Staphylococcus aureus & 78 & 50.32 \\
Streptococcus sp. & 8 & 5.16 \\
Neisseria gonorrhoea & 2 & 1.29 \\
Pseudomonas sp. & 24 & 15.48 \\
Coagulase-ve Staph. & 15 & 9.68 \\
Proteus mirabilis & 7 & 4.52 \\
Candida albicans & 8 & 5.16 \\
Total & $\mathbf{1 5 5}$ & $\mathbf{1 0 0}$ \\
\hline
\end{tabular}

Olatunji and Sule-Odu recorded $48.2 \%$ from an earlier study in the hospital [16]. The slight increase noticed here might have to do with more people resulting to solving their infertility problems through orthodox means. In a similar study carried out at the Eastern part of Nigeria, $60 \%$ of the male were Oligospermic, $13 \%$ was recorded in Tunisia while $45.3 \%$ was recorded in IIorin, North-Central part of Nigeria [6,12,18-20].

The variation noted above may be a matter of concern. Although geographical differences had been reported to have no major effect on semen quality [21], other factors may need to be considered, such as the pattern of normal sperm count in the areas of study.

Semen analysis though routinely used to evaluate the male partner in an infertile marriage, sperm measurements that discriminate between fertile and infertile men are not well defined [22].

Infection has remained one of the important factors in infertility especially among the secondary infertility group. Pathogenic micro-organisms were isolated in $47.1 \%$ of semen samples of men in infertile marriages in Benincity, 7\% in Ilorin and 16\% in Enugu $[6,12,15,18]$.

In this study, $32.4 \%$ of semen samples examined were infected. The isolation of Staphylococcus aureus in $50.3 \%$ of the infected cases might be associated with body hygiene of the couples involved. However, crossinfection cannot be ruled out as few couples confessed cases of "trying outside marriage". This finding agrees with other published works [15,23].

Relationship between low sperm motility and infection becomes obvious in this study as $88.6 \%$ asthenozoospermic cases were infected. This group may benefit from simple therapeutic procedures. This often becomes very difficult, due to economic status of many in this group. The cost of drugs, duration of medication, follow up investigations and cultural belief are few of the obstacles that might work against achieving fertility even in these diagnosed cases. The $2.7 \%$ azoospermic cases with infection in this study will benefit from adequate treatment at least to have good health and reduce cross-infection.

Greater percentage of cases in this study (80.4\%) presented with $2^{\circ}$ infertility, this agrees with the work of Nwabuisi and Onile. The higher cases of $2^{\circ}$ infertility might be due to post infective causes which are common in Africa [2,18].

Most causes of infertility due to male factor are reversible if clinician's prescriptions are religiously followed and patients are well informed. This education should include information on how STI's cause infertility in women and men at anytime in their reproductive years. 


\section{Limitation}

The supply of antibiotic sensitivity discs were inconsistent (variations in product types), hence the antibiotic sensitivity pattern of the isolates could not be collated.

\section{Acknowledgements}

The authors are grateful to all the members of staff of the Department of Medical Microbiology and Parasitology of OOUTH for maintaining consistent analytical method and proper record keeping. Your support is appreciated.

\section{REFERENCES}

[1] E. C. K. Mening, "Emotional Needs of the Infertile Couple,” Fertility and Sterility, Vol. 34, 1980, pp. 313-314.

[2] A. A. Jimoh, "The Management of Infertility in Africa," Medilor, Vol. 1, No. 1, 2002, pp. 3-9.

[3] J. B. O’Fallon, “Unmet Fertility Expectations and the Perception of Fertility Problems in a Malawian Village," African Journal of Reproductive Health, Vol. 9, No. 2, 2005, pp. 14-25. doi:10.2307/3583459

[4] O. A. Ladipo, "Epidemiology of Infertility," Dokita, Vol. 16, No. 1, 1986, pp. 1-5.

[5] I. D. Cook, "Infertility," In: O. K. Edmonds, Ed., Dewhursts Textbook of Obstetrics and Gynaecology for Postgraduate, 6th Edition, Blackwell Science Ltd., 1999, pp. 432-440.

[6] M. A. S. Ezenyirioha and J. P. C. Ajaebili, "Seminal Fluid Characteristics of Men Attending an Infertility Clinic in Enugu-Nigeria,” Orient Journal of Medicine, Vol. 6, No. 1-2, 1994, pp. 24-26.

[7] F. Okonofua, "Infertility and Women's Reproductive Health in Africa," African Journal of Reproductive Health, Vol. 3, No. 1, 1999, pp. 7-9.

[8] M. A. Basley, "Epidemiology of Infertility," Bulletin of the World Health Organization, Vol. 54, 1976, pp. 319341.

[9] W. Cates, T. M. M. Farley and A. Rowe, "Worldwide Patterns of Infertility-Is Africa Different?” Lancet, Vol. 2, No. 8455, 1985, pp. 596-598. doi:10.1016/S0140-6736(85)90594-X

[10] R. Hauser, G. Paz, A. Botchan, L. Yoger and H. Yaretz, "Varicocele: Effect on Sperm Functions," Human Reproduction Update, Vol. 7, No. 5, 2001, pp. 482-485. doi:10.1093/humupd/7.5.482

[11] S. Kenkel, C. Rolf and E. Nieschlag, "Occupational Risks for Male Fertility: An Analysis of Patients Attending a
Tertiary Referral Center,” International Journal of Andrology, Vol. 24, No. 6, 2001, pp. 318-326. doi:10.1046/j.1365-2605.2001.00304.x

[12] R. Gdoura, L. Keskes-Ammar and F. Bouzid, "Chlamydia Trachomatis and Male Infertility in Tunisia," European Journal of Contraception and Reproductive Health Care, Vol. 6, No. 2, 2001, pp. 102-107.

[13] S. E. Chia and S. K. Tay, "Occupational Risk for Male Infertility: A Case-Control Study of 218 Infertile and 227 Fertile Men,” Journal of Occupational \& Environmental Medicine, Vol. 43, No. 11, 2001, pp. 945-951. doi:10.1097/00043764-200111000-00004

[14] World Health Organization, "Laboratory Manual for the Examination of Human Semen and Sperm-Cervical Mucus Interaction,” Cambridge University Press, Cambridge, 1992.

[15] S. O. Onemu and I. N.Ibeh, "Studies on the Significance of Positive Bacterial Semen Cultures in Male Fertility in Nigeria,” International Journal of Fertility and Women's Medicine, Vol. 46, No. 4, 2001, pp. 210-214.

[16] A. O. Olatunji and A. O. Sule-Odu, "The Pattern of Infertility Cases at a University Hospital," West African Journal of Medicine, Vol. 22, No. 3, 2003, pp. 205-207.

[17] S. T. Cowan, "Cowan and Steel Manual for Identification of Medical Bacteria,” 2nd Edition, Cambridge University Press, Cambridge, 1974.

[18] C. Nwabuisi and B. A. Onile, "Male Infertility among Sexually Transmitted Disease Clinic Attendees in Ilorin," Nigerian Journal of Medicine, Vol. 10, No. 2, 2001, pp. 68-71.

[19] W. O. Chukwudebelu, "The Male Factor in Infertility; The Nigerian Experience,” International Journal of Infertility, 1978, pp. 23-38.

[20] D. S. Guzick, J. W. Overstreet and P. Factor-Litrak, "Sperm Morphology, Motility and Concentration in Fertile and Infertile Men," The New England Journal of Medicine, Vol. 345, No. 19, 2001, pp. 1388-1393. doi:10.1056/NEJMoa003005

[21] T. K. Jensen, R. Slama and B. Ducot, "Regional Differences in Waiting Time to Pregnancy among Fertile Couples from Four European Cities,” Human Reproduction Vol. 16, No. 12, 2001, pp. 2697-2704. doi:10.1093/humrep/16.12.2697

[22] R. P. Amann, "Can the Fertility Potential of a Seminal Sample Be Predicted Accurately?” Journal of Android, Vol. 10, 1989, pp. 89-98.

[23] F. T. Andrade-Rocha, "Sperm Parameters in Men with Suspected Infertility,” Journal of Reproductive Medicine, Vol. 46, No. 6, 2001, pp. 577-582. 